\title{
5 ociuger
}

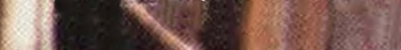

www flacsoandes.edu.ec

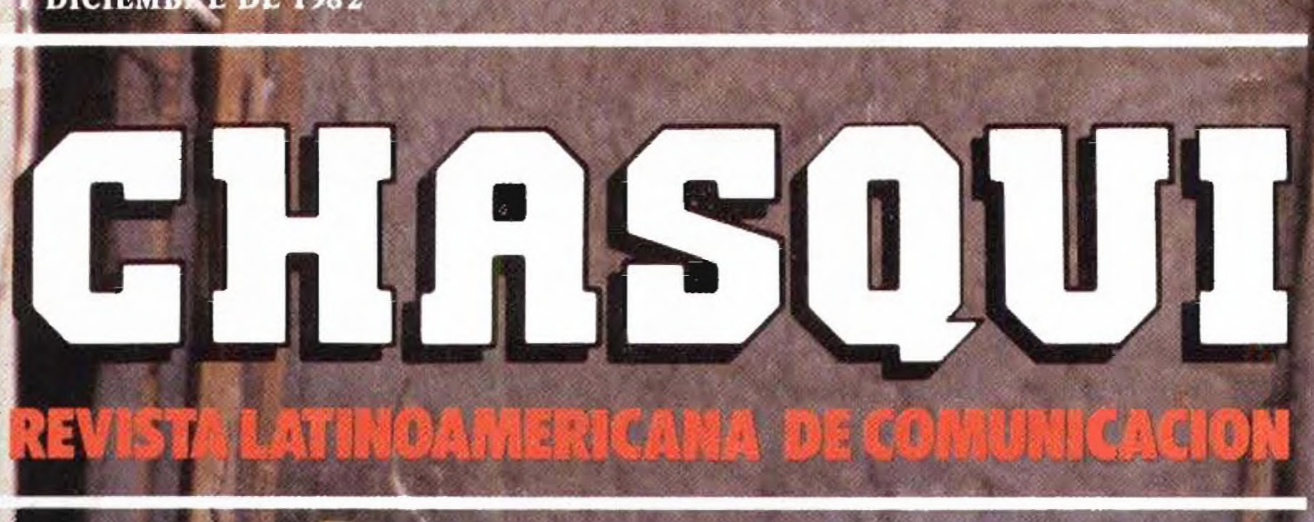

\section{$\exists$}
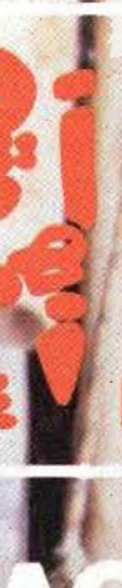

ION COOMUNICACION

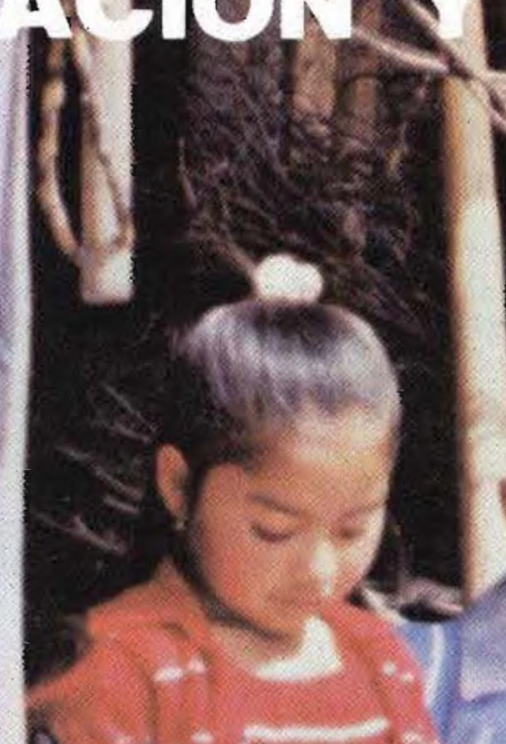

ace
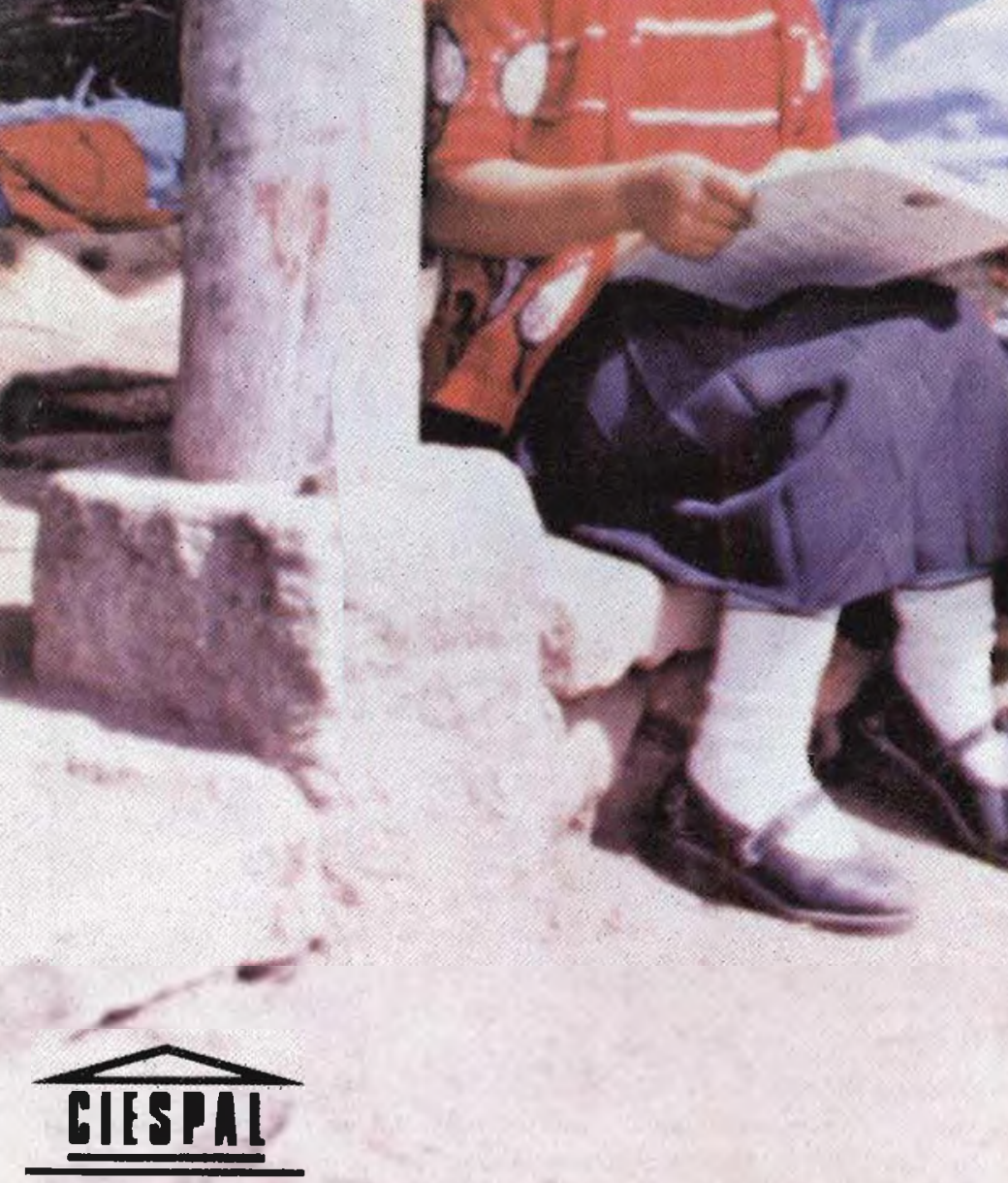

\section{De Zutter - Urioste} Matayoshi - Prieto 


\section{En este número}

\section{Carta de los Editores}

Thtimado lector, este námero especial de CHASOUI se Ocupa básicamente de las ponencias, experiencias y documentos que se presentaron y discutieron durante el "Seminario Regional sobre métodos y procedímientos de comunicación en función del Proyecto Principal de Educación en América Latina y el Caribe" que se realizó en Quito, sede de CIESPAL, a fines de septiembre de 1982. La Ofícina Regional de Educación de la UNESCO para América Latina y CIESPAL, que tuvieron a su cargo la organización del evento, decidieron la publicación de este número especial de CHASQUI como un nuevo aporte al diálogo y a la integración entre comunicadores y educadores.

Dada la importancia de la temática, la calidad de los trabajos y el nivel de díscusión del Seminario, la revista CHASOUT y los organizadores acordaron la realización de un Panel para tratar sobre "El uso de los medios masivos en los procesos educativos', en el que participaron seis especialistas y cuyo contenido constítuye parte central de la revista.

El Editorial escrito por el director de CIESPAL, Dr. Luis E. Proaño, se ocupa de algunos tópicos analizados durante el Seminarío.

En la sección Ensayos tenemos tres ponencias presentadas por Díaz Bordenave, Urioste y de Zutter asi como la experiencia de Nicolás Matayoshì en la sierra del Perá.

Nuestra sección Experiencias de Proyectos trae en este número las aportaciones en función del Proyecto Principal que los participantes al Seminario, todos especialistas integrados a trabajos especificos, llámanse estatales, privados o populares, expusieron en Quito, mientras que la sección Controversia presenta los puntos de vista de la brasileña Delcia Enricone y del francés Pierre de Zutter. En Nuevas Tecnologías tenemos la colaboración del investigador Daniel Prieto Castillo que escribió sobre "Educación, tecnologías y futuro", referida a parte de una investigación organizada por el ILCE en México y en la que el autor del artículo tuvo destacada participación.

CHASOUI ofrece de esta manera una visión panorámica de lo que fue este importante Seminario Regional donde el papel de la Comunicación y la Educación se vieron permanentemente entrelazados. En próximos números seguiremos informando sobre los adelantos en relación a la comunicación dentro de los objetivos del Proyecto Principal en los diferentes países y sobre las nuevas experiencias adquiridas a partir del Seminario de Quito.

$$
\text { Lo saludan, }
$$

Ronald Grebe López - Jorge Mantilla
2 EDITORIAL

Educación y Comunicación.

Dr. Luis E. Proaño.

4 PANEL

14 ENSA YOS.

14 Democratización de la Comunicación, Democratización de la Educación. Juan Díaz Bordenave.

25 Prioridades y criterios para estrategias comunicativas.

Miguel Urioste.

35 Educación Popular:

¿Medios masivos o comunicación interpersonal? Pierre de Zutter.

43 Identidad étnica y recuperación cultural. Nicolás Matayoshi.

48 EXPERIENCIAS DE PROYECTOS.

58 CONTROVERSIA.

65 NUEVAS TECNOLOGIAS.

Educación:

Tecnologías y futuros.

Daniel Prieto Castillo.

74 ACTIVIDADES DE CIESPAL.

77 NOTICIAS.

94 DOCUMENTOS.

94 El Proyecto Principal.

99 Declaración de México.

101 Declaración de Quito.

106 Declaración de Ciudad de México sobre las políticas culturales.

110 BIBLIOGRAFIA.

115 HEMEROGRAFIA EUROPEA

119 ENGLISH SECTION 


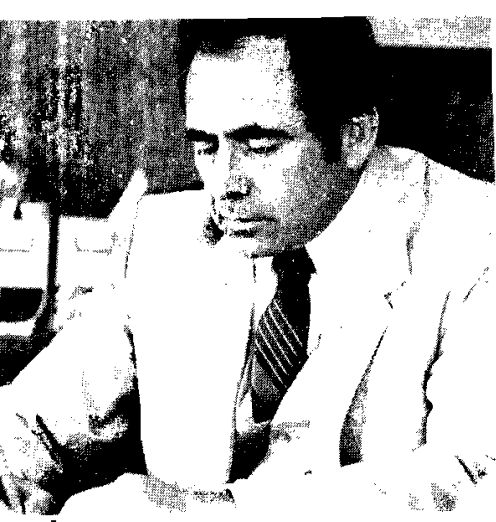

COMUNICACION

DR. LUIS E. PROAÑO

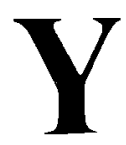
EDUCACION

$\mathbf{E}$ ducación y comunicación son dos términos muy debatidos y debatibles. Son dos concep tos que se prestan a las más diversas interpretaciones. Son dos palabras que se oyen diaria y continuamente en nuestro medio $y$ alrededor de las cuales se diserta, se escribe y se formulan soluciones. Casi se podría decir que no hay intelectual que merezca el nombre de tal que no haya acuñado su propio concepto y su propio significado de educación y comunicación.

La comunicación es un ingrediente de toda actividad humana. Por eso es lógico deducir que el fracaso del quehacer del hombre, sea en las tareas del desarrollo como en las de la política, cultura y educación, se debe a un fracaso en la comunicación. Anticipo, sin embargo, un punto que considero de capital importancia: Si es verdad que la educación necesita de la comunicación, también es verdad que no podrá haber excelencia en la comunicación si no media una educación para comunicarse.

Tres son los escollos que quiero mencionar en principio: 1) La verticalidad y manipulación del mensaje; 2) la creencia en la omnipotencia de los medios de comunicación; y, 3) la falta de educación crítica para la comunicación.

El siglo XX, si se lo compara con los anteriores, puede llamarse sin exageración el siglo de las comunicaciones. En él se hicieron descubrimientos y se desarrollaron tecno logías que pueden unir al hombre, por remota que sea su ubicación, con el resto de la humanidad, instantáneamente on el lapso de unos cuantos minutos.

El telégrafo, el teletipo, télex y teléfono; el uso múltiple del espectro radiofónico a partir de los primeros éxitos de Marconi, hasta perforar la ionósfera y adentrarse en el espacio exterior; los satélites geoestacionarios a 36.000 kilómetros de la tierra, capaces de transmitir simultáneamente miles de mensajes; la aplicación de la tecnología de las computadoras a las telecomunicaciones; la transmisión de sonidos e imágenes por fibras ópticas y rayos laser; la proliferación de aparatos magnetoscópicos y la televisión numérica, abruman al hombre con increibles posibilidades de intercomunicarse.
Hay suficiente eficiencia para creer que el hombre de nivel cultural medio gasta el setenta por ciento de sus horas de vigilia comunicándose: escuchando, hablando, leyendo $y$ escribiendo, en ese orden de importancia. Querria decir que emplea de diez a once de las horas diarias hábiles en comunicación verbal.

$\mathbf{L}$ os futurólogos aseguran que al perfeccionarse las fibras ópticas habrá de veinte a ochenta canales disponibles en los hogares. Mediante un sistema de computación se recibirá la información de todos los periódicos; se podrá ver, las veces que se quiera, los programas predilectos de televisión y las peliculas más recientes; se desarrollará un sistema de comunicación personalizada según los intereses individuales; se perfeccionarán a través de computadoras los servicios de información respecto a la economia, la protección policial, el cuidado de la salud, la marcha de la vida política; la educación permanente y abierta será una realidad, empleando mejor las horas de ocio en el contacto de profesores, la recepción de sus clases, la consulta a bibliotecas, la presentación de exámenes que permitirán graduarse desde el hogar.

Este impresionante desarrollo de los mecanismos que canalizan la comunicación humana, sitúa al hombre ante una encrucijada de amenaza o esperanza; de ser posible esclavitud o libertad.

Sintetizando la crítica fundamental podríamos decir que la amenaza de la manipulación de los medios de comunicación se concentra en los siguientes puntos:

1.- Los medios le dicen al hombre perdido en la masa quién es él. Es decir le dan identidad.

2.- Los medios le dicen al hombre qué es lo que debe desear ser, es decir, le dan aspiraciones.

3.- Los medios le dicen al hombre cómo llegar a realizar esas aspiraciones, es decir, le enseñan una técnica y un mecanismo.

4.- Los medios finalmente le dicen al hombre cómo debe sentirse siendo lo que es (aunque no lo sea), es decir, le proveen de un escape. 
La brecha entre su identidad y sus aspiraciones lo conducen necesariamente a la técnica y al escapismo. Esta, dicen los críticos, es la fórmula básica sicológica de los medios de comunicación contemporáneos. Pero como fórmula, no está a tono con el desarrollo de la raza humana. Es una fórmula de un seudo mundo, que los medios pueden inventar y luego mantener hasta que sea absorbida por los individu os como parte integrante de su identidad. Esta teoría y su critica consecuente lleva latente la creencia en la omnipotencia de los medios para manipular a gusto la conciencia y los valores del individuo. Si esta teoría fuera verdadera tendríamos razón para sentirnos supremamente amenazados. Por suerte la investigación de la comunicación nos ha indicado suficientemente cuales son los límites de los medios para la conformación de actitudes y valores de la sociedad.

De aquí nace nuestra esperanza: Los medios, de acuerdo con las últimas investigaciones, no juegan otro papel que el de ser sumamente eficaces como mecanismos de apoyo a los valores $y$ actitudes primarios del individuo, es decir, aquellos que conforman su identidad personal como fruto de la educación que se da en la familia y de la educación que más tarde se da a través de la escuela, el colegio y la universidad. En otras palabras, el que podamos liberarnos de la amenaza de la futura tecnología de comunicación dependerá en gran medida de la calidad de nuestra educación. Pero sea cual fuere el modelo educativo que adoptemos, su calidad dependerá de que evitemos la unilateralidad vertical en la transmisión del mensaje y carguemos el acento en la necesidad de la interacción, la mutua información, el intercambio de experiencia y conocimientos. Supondrá la apertura, la aceptación mutua, la reciprocidad y el bilateral enriquecimiento. Por eso la participación de los grupos comunitarios tendrá que englobarse a lo largo de todo el proceso educativo desde el análisis de la situación y definición de objetivos hasta el de la ejecución, control y evaluación.

En este contexto, la utilización de los medios de comunicación, servirá para firmar la decisión tomada en una labor de cogestion entre población y organismo educador y para informar de la marcha de los programas adoptados y la consecución de los objetivos. El contenido de los mensajes difundidos a través de esos medios sean los masivos o los comunitarios; los de alto o bajo costo; deben nacer y generarse en la población y volver a ella en un ininterumpido proceso de retroalimentación. Debemos alejar definitivamente la tentación de la manipulación de los mensajes y la imposición de la comunicación vertical.

$\mathbf{E}$ sto es importante sobre todo cuando se trata de la educación de los grupos marginales o de las minorías raciales de la nación. Se ha supuesto, gratuitamente, sin tomarse el esfuerzo para medir el vigor de los argumentos, que el ejercicio crítico del entendimiento es patrimonio exclusivo de la educación formal. Por consiguiente, la gran masa de la población latinoamericana que está compuesta de campesinos y obreros, tradicionalmente excluidos de los centros de educación, son incapaces de un juicio critico que merezca tomarse en cuenta. Las élites cultas se han creido destinadas a descubrir lo que esa muchedumbre ignara necesita. Se hadado por descontado que todo diálogo es improductivo y estéril y en consecuencia se ha asignado a los medios de comunicación el papel de sacudir la apatía de la población en función de planes de educación elaborados en los centros de decisión. Toda comunicación y educación, en su minima expresión, supone un hombre que actúa y otro que responde. Es en realidad una acción continua, flujo y reflujo, en que intervienen dos sujetos agentes de ella, yo y el otro, acción en que va inserta, interpretada e involucrada la del otro y que es, por tanto, interacción, reciprocidad. Pero como los medios de comunicación colectiva son incapaces estructuralmente de recibir la respuesta en forma directa, inmediata y masiva a los mensajes que envia, para no destruir su labor comunicadora hace falta estructurar formas y modos de recoger la respuesta, asi sea indirecta y cumulativamente.

Este numero de CHASQUI ofrece una visión panorámica de los problemas y perspectivas planteadas durante el Seminario Regional sobre Métodos y Procedimientos de Comunicación Social en función del Proyecto Principal de Educación en América Latina y el Caribe llevado a cabo en acción conjunta por la UNESCO y CIESPAL a fines de septiembre de 1982. 